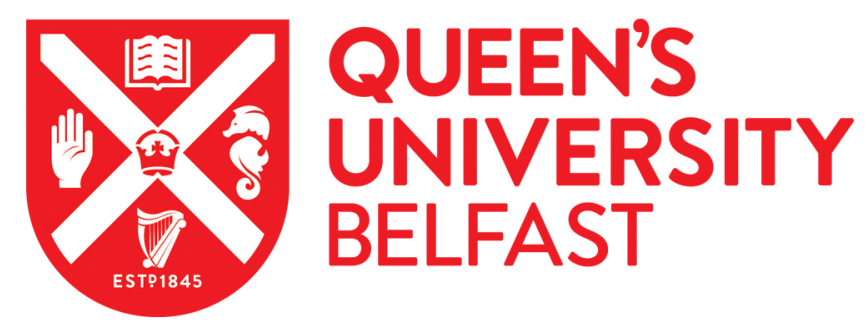

\title{
Plasma fibrinogen explains much of the difference in risk of coronary heart disease between France and Northern Ireland. The PRIME study
}

Scarabin, P. Y., Arveiler, D., Amouyel, P., Santos, C. D., Evans, A., Luc, G., Ferrieres, J., \& Juhan Vague, I. (2003). Plasma fibrinogen explains much of the difference in risk of coronary heart disease between France and Northern Ireland. The PRIME study. Atherosclerosis, 166(1), 103-109.

\section{Published in:}

Atherosclerosis

Queen's University Belfast - Research Portal:

Link to publication record in Queen's University Belfast Research Portal

\section{General rights}

Copyright for the publications made accessible via the Queen's University Belfast Research Portal is retained by the author(s) and / or other copyright owners and it is a condition of accessing these publications that users recognise and abide by the legal requirements associated with these rights.

Take down policy

The Research Portal is Queen's institutional repository that provides access to Queen's research output. Every effort has been made to ensure that content in the Research Portal does not infringe any person's rights, or applicable UK laws. If you discover content in the Research Portal that you believe breaches copyright or violates any law, please contact openaccess@qub.ac.uk. 


\title{
Plasma fibrinogen explains much of the difference in risk of coronary heart disease between France and Northern Ireland. The PRIME study
}

\author{
Pierre-Yves Scarabin ${ }^{\mathrm{a}, *}$, Dominique Arveiler $^{\mathrm{b}}$, Philippe Amouyel ${ }^{\mathrm{c}}$, Carla Dos Santos ${ }^{\mathrm{a}}$, \\ Alun Evans ${ }^{\mathrm{d}}$, Gérald Luc $^{\mathrm{e}}$, Jean Ferrières ${ }^{\mathrm{f}}$, Irène Juhan-Vague ${ }^{\mathrm{g}}$ \\ ${ }^{a}$ Cardiovascular Epidemiology Unit U258, INSERM, 16, Avenue Paul Vaillant-Couturier, 94807 Villejuif Cedex, France \\ ${ }^{\mathrm{b}}$ MONICA-Strasbourg, Laboratoire d'Epidémiologie et de Santé Publique, Strasbourg, France \\ ${ }^{\mathrm{c}}$ MONICA-Lille, Institut Pasteur de Lille, Lille, France \\ ${ }^{\mathrm{d}}$ Department of Epidemiology and Public Health, Queen's University Belfast, Belfast, UK \\ ${ }^{\mathrm{e}}$ SERLIA Laboratory, INSERM U325 and Pasteur Institute, Lille, France \\ ${ }^{\mathrm{f}}$ MONICA-ORSMIP, Faculté de Médecine Purpan, Toulouse, France \\ ${ }^{\mathrm{g}}$ Laboratory of Haemostasis, Hôpital la Timone, Marseille, France
}

Received 14 April 2002; received in revised form 8 July 2002; accepted 26 July 2002

\begin{abstract}
The incidence of coronary heart disease is higher in Northern Ireland than in France. These differences have not been adequately explained. We have investigated the associations of plasma fibrinogen concentration and factor VII activity with the incidence of coronary heart disease in a prospective cohort study involving 10600 men aged 50-59 living in four regions (Lille, Strasbourg, and Toulouse in France, Belfast in Northern Ireland). Baseline fibrinogen and factor VII were measured in 9489 men free of coronary heart disease at entry (7167 in France and 2322 in Northern Ireland). Over 5 years of follow-up, 161 participants developed myocardial infarction (MI) or coronary death (100 in France and 61 in Belfast) and 151 developed angina pectoris (94 in France and 57 in Belfast). The risk of future coronary events was 1.9 times higher in Belfast than in France (95\% confidence interval: 1.5-2.4). Baseline mean levels of fibrinogen were significantly higher in Belfast than in France and they were higher in participants who experienced coronary events compared with those who did not in both countries. The age-adjusted relative risk of coronary heart disease associated with a rise of one standard deviation in fibrinogen level was $1.56(95 \%$ confidence interval: $1.29-1.95, P<0.0001)$ in the whole cohort. This association remained significant after adjustment for other cardiovascular risk factors (relative risk:1.36; 95\% confidence interval: $1.14-1.68 ; P<0.0001)$. There was no clear geographical variation in factor VII and no significant association between factor VII levels and the risk of coronary events was observed. Classic risk factors explained $25 \%$ of the excess risk of coronary heart disease in Belfast compared with France, while fibrinogen alone accounted for 30\%. These findings add to the epidemiological evidence that elevated fibrinogen is a major risk factor for coronary heart disease.
\end{abstract}

(C) 2002 Elsevier Science Ireland Ltd. All rights reserved.

Keywords: CHD; Fibrinogen; Factor VII

\section{Introduction}

Large geographical variations in myocardial infarction (MI) have been observed in European countries. Data from the World Health Organization MONICA

\footnotetext{
* Corresponding author. Tel.: +33-1-45-59-5112; fax: +33-47-269454

E-mail address: scarabin@vjf.inserm.fr (P.-Y. Scarabin).
}

Project (multinational monitoring of trends and determinants in cardiovascular disease) showed a higher incidence of coronary heart disease (CHD) in Northern Ireland than France [1]. Age-standardised annual event rates per 1000000 men aged 35-64 averaged 306 in three French regions and 807 in Belfast [1]. Differences in the distribution of classical risk factors can explain only a small part of the excess risk of CHD in Belfast compared with France [2,3]. Over the last 10 years, haemostatic variables have emerged as novel risk 
markers for CHD [4] and early epidemiological evidence has associated high levels of plasma fibrinogen and factor VII activity with CHD incidence [5,6]. Many studies have confirmed the importance of fibrinogen as a strong risk marker for CHD [7,8] but further data have yielded conflicting results about factor VII and CHD prediction [4].

In the Prospective Epidemiological Study of Myocardial Infarction (PRIME) Study, we investigated the contribution of fibrinogen and factor VII to the prediction of 5-year CHD incidence in men aged 50-59 in France and Northern Ireland. Furthermore, we assessed the extent to which fibrinogen and factor VII could explain the difference in CHD incidence between these two countries.

\section{Methods}

\subsection{Study population}

The PRIME design has been published [3]. The three WHO MONICA field centers in France (Lille, Strasbourg and Toulouse) and the center in Northern Ireland (Belfast) each recruited approximately 2500 men aged 50-59 years. The participants were recruited between 1991 and 1993 from both industrial and community settings. Subjects were informed of the aim of the study and those who agreed to take part were given a morning appointment and asked to fast for at least $12 \mathrm{~h}$. Local ethical committees approved the study.

\subsection{Clinical measurements}

Baseline self-administered questionnaires were completed at home by participants and included assessment of health behaviors, sociodemographic factors, and history of cardiovascular disease and diabetes mellitus. The questionnaires were checked at the clinic by an interviewer who sought information on missing items. Anthropometric measurements included height and weight, and blood pressure was measured on two occasions in the sitting position with the same automatic device (Spengler SP9). During the examination, the questionnaire on personal medical history was completed along with the London School of Hygiene Cardiovascular (Rose) Questionnaire for Chest Pain on Effort and Possible Infarction [9], and a 12-lead electrocardiogram was recorded.

Subjects were considered free of CHD at entry if none of these criteria was met: (1) reported MI and/or angina pectoris diagnosed by a physician; (2) electrocardiographic evidence of MI, defined as major or moderate Q waves on Minnesota coding; (3) a positive answer to the Rose Questionnaire. Prevalent hypertension was defined as systolic pressure $>150 \mathrm{mmHg}$, diastolic pressure $>$
$95 \mathrm{mmHg}$, or use of antihypertensive agents. Prevalent diabetes mellitus was defined as a self-reported history of physician-diagnosed diabetes and/or use of antidiabetic agents. The body mass index was computed as weight $(\mathrm{kg})$ divided by height squared $\left(\mathrm{m}^{2}\right)$.

\subsection{Blood sampling and assay procedures}

Laboratory procedures have been published [11]. Venous blood (nine volumes) was collected between 9:00 and 10:00 $\mathrm{h}$ into siliconised vacutainer tubes (Vacutainer, Becton Dickinson) containing $0.11 \mathrm{M}$ trisodium citrate (one volume). Platelet-poor plasma was obtained by centrifugation at $4500 \times g$ and $20{ }^{\circ} \mathrm{C}$ for $15 \mathrm{~min}$. Without delay, aliquots of plasma were transferred into plastic tubes and frozen on-site to $80{ }^{\circ} \mathrm{C}$, and then they were shipped in batch to the central laboratory in Lille.

Fibrinogen and factor VII were measured in the central haemostasis laboratory of La Timone Hospital at Marseille, France. Fibrinogen was measured according to the method of Clauss [12]. Factor VIIc was assayed in a regular one-stage system using rabbit brain thromboplastin obtained from Diagnostic Reagents Limited (Oxon, England). Factor VII-deficient substrate plasma was prepared from absorbed bovine plasma and concentrate of human factors IX, X, and II as described [13]. Factor international standard was obtained from NIBSC (National Institute for Biological Standard and Control, Hertfordshire, England). Results were expressed as a percentage of the reference plasma.

Accuracy and precision of haemostatic assays were assured by a strict internal quality control program. A single batch of normal plasma pool prepared from 50 healthy subjects was used as a control material. Analysis of internal quality control data showed that laboratory coefficient of variation was $4.3 \%$ for fibrinogen and $7.2 \%$ for factor VII.

Plasma prepared with EDTA was used for analysis of lipids. Plasma total cholesterol and triglycerides were measured by enzymatic methods using reagents obtained from Boerhinger Mannhein (Mannhein, FRG). High density lipoprotein (HDL)-cholesterol was measured after sodium phosphotungstate-magnesium chloride precipitation.

\subsection{Follow-up}

The follow-up procedures have been described in detail [10]. Subjects were contacted annually by letter and asked to complete a clinical event questionnaire. If the subject did not comply, phone contact was established with him or his general practitioner. For all subjects reporting a possible event, the hospital records and physician records were collected. Death certificates were checked for supporting clinical and post-mortem 
information on cause of death. Whenever necessary, the circumstances of death were obtained from the practitioner or the family. Validation of coronary events was done by the PRIME Medical Committee according to a strict protocol.

MI was defined by one of the following sets of conditions: (1) new diagnostic $\mathrm{Q}$ wave or other fresh typical electrocardiographic sign of necrosis; (2) typical or atypical pain symptoms and new (or increased) ischaemia and myocardial enzyme levels higher than twice the upper limit; (3) post-mortem evidence of fresh MI or thrombosis.

Definite coronary death was defined as death with a documented coronary event. Sudden death was defined as death occurring within $1 \mathrm{~h}$ following symptoms without explanation. When a coronary death was suspected, with no documentation or explanation it was labeled possible coronary death. The three death categories were grouped together as coronary deaths.

Angina pectoris was defined by the presence of chest pain at rest and/or on exertion and one of the following criteria: (1) angiographic stenosis over $50 \%$; or (2) a positive scintigraphy (if no angiographic data); or (3) positive exercise stress test (if no angiographic or scintigraphic data); or (4) electrocardiogram changes at rest (if no angiographic, scintigraphic or exercise stress test data), but without MI and no evidence of a non-coronary cause in the clinical history. Unstable angina was defined as a crescendo pain or chest pain at rest, with either enzyme changes or electrical changes.

\subsection{Statistical analysis}

Statistical analysis used procedures available in the STATISTICAL ANALYSIS SYSTEM (SAS) software (SAS Institute, Inc., Cary, NC). Distribution of fibrinogen was positively skewed and so $\log$ transformed values were used. Mean levels of fibrinogen are given in arithmetic form. Data analysis was stratified by both country and vascular end points (hard events and angina pectoris) after pooling the three French centers. Twoway analysis of variance and chi-square test were used to compare the characteristics of cases and control subjects. Homogeneity of the results across the countries was systematically tested by including interaction terms into the statistical models. Age-adjusted relative risks of CHD per one standard deviation of each haemostatic variable were estimated using multiple logistic regression. Relative risks were further adjusted for conventional cardiovascular risk factors. Finally, unadjusted and adjusted relative risks of CHD in Northern Ireland versus France were used to estimate the excess risk explained by fibrinogen and conventional risk factors. Relative risks are given with $95 \%$ confidence intervals, and two sided probability values are used.

\section{Results}

Haemostatic variables were available for 9489 participants free of CHD at baseline. Over 5 years of followup, 161 participants developed MI or coronary death (100 in France and 61 in Belfast) and 151 developed angina pectoris (94 in France and 57 in Belfast). The risk of future coronary events was 1.9 times higher in Belfast than in France (95\% confidence interval: 1.5-2.4).

Baseline mean levels of fibrinogen were substantially higher in Northern Ireland than in France (overall mean increase $+45 \mathrm{mg} / \mathrm{dl}, P<0.001$ ), whereas a minor but significant difference in factor VII activity between the two countries was observed (Table 1). Levels of established vascular risk factors were generally higher in subjects who developed hard CHD or angina than in those who remained free of CHD (Table 1). Mean levels of fibrinogen but not those of factor VII were significantly higher in subjects with subsequent CHD events than in those without in both France and Northern Ireland (overall mean increase +21 and $+36 \mathrm{mg} / \mathrm{dl}$, respectively). There was no significant difference in fibrinogen levels between subjects who developed effort angina $(n=111)$ and those who did unstable angina $(n=40)$. Table 2 provides the relative risks of CHD per one standard deviation increase in fibrinogen in both France and Northern Ireland. In France, age-adjusted incidence of CHD was 36\% higher per S.D. increment (101 mg/dl) of fibrinogen. In Northern Ireland, CHD incidence was 59\% higher per each S.D. increment in fibrinogen. Adjustment for classical vascular risk factors slightly reduced the relative risks; the association between fibrinogen and CHD incidence remained significant in both France and Northern Ireland.

Table 3 gives the relative risks of CHD in Northern Ireland compared with France before and after adjustment for classical risk factors and fibrinogen. Classic risk factors explained $25 \%$ of the excess risk of CHD in Belfast compared with France, while fibrinogen alone accounted for $30 \%$. Together, fibrinogen and classical risk factors explained $44 \%$ of the difference in CHD incidence between the two countries. With respect to the vascular endpoints (hard CHD or angina) similar results were observed. Educational level was lower in Northern Ireland than in France but this difference explained only $2 \%$ of the excess risk of CHD in Belfast.

\section{Discussion}

This prospective cohort study shows that elevated fibrinogen level is an independent predictor of CHD among healthy middle-aged men in both France and Northern Ireland. Furthermore, fibrinogen levels are substantially higher in Northern Ireland than in France and this contrast explains an important part of the 
Table 1

Distributions of risk factors for CHD according to the incidence of coronary events and country among men aged 50-59 years at entry

\begin{tabular}{|c|c|c|c|c|c|c|c|c|c|}
\hline \multirow[t]{2}{*}{ Factor } & \multicolumn{3}{|c|}{ Northern Ireland } & \multicolumn{3}{|l|}{ France } & \multicolumn{3}{|c|}{ Test of differences } \\
\hline & $\begin{array}{l}\text { No CHD } \\
(n=2204)\end{array}$ & $\begin{array}{l}\text { Hard CHD } \\
(n=61)\end{array}$ & $\begin{array}{l}\text { Angina } \\
(n=57)\end{array}$ & $\begin{array}{l}\text { No CHD } \\
(n=6973)\end{array}$ & $\begin{array}{l}\text { Hard CHD } \\
(n=100)\end{array}$ & $\begin{array}{l}\text { Angina } \\
(n=94)\end{array}$ & $\begin{array}{l}\mathrm{N} \text { Ireland vs. } \\
\text { France }\end{array}$ & $\begin{array}{l}\text { Hard CHD vs. no } \\
\text { CHD }\end{array}$ & $\begin{array}{l}\text { Angina vs. no } \\
\text { CHD }\end{array}$ \\
\hline Age (years) & $54.7(2.9)$ & $55.4(2.8)$ & $55.2(2.9)$ & $54.9(2.9)$ & $55.6(3.0)$ & $55.4(2.9)$ & 0.004 & 0.006 & 0.05 \\
\hline BMI $\left(\mathrm{kg} / \mathrm{m}^{2}\right)$ & $26.1(3.4)$ & $26.7(3.6)$ & $26.9(3.0)$ & $26.7(3.4)$ & $27.1(3.6)$ & $28.0(4.0)$ & $<0.001$ & 0.16 & $<0.001$ \\
\hline \multicolumn{10}{|l|}{ Smoking status $(\%)$} \\
\hline Current & 30.9 & 42.6 & 36.8 & 25.0 & 40.0 & 31.9 & $<0.001$ & $<0.001$ & 0.04 \\
\hline Past & 33.5 & 36.1 & 35.1 & 47.1 & 37.0 & 51.1 & $<0.001$ & 0.07 & 0.77 \\
\hline Never & 35.6 & 21.3 & 28.1 & 27.9 & 23.0 & 17.0 & $<0.001$ & 0.04 & 0.02 \\
\hline $\mathrm{SBP}(\mathrm{mm} / \mathrm{Hg})$ & $133(20)$ & $137(24)$ & $147(23)$ & $133(18)$ & $138(21)$ & $140(21)$ & 0.47 & 0.002 & $<0.001$ \\
\hline Cholesterol $(\mathrm{mmol} / \mathrm{l})$ & $5.85(1.00)$ & $6.08(1.06)$ & $6.20(1.05)$ & $5.64(0.95)$ & $5.85(0.88)$ & $6.01(1.03)$ & $<0.001$ & 0.003 & $<0.001$ \\
\hline $\begin{array}{l}\text { HDL-cholesterol } \\
(\mathrm{mmol} / \mathrm{l})\end{array}$ & $1.19(0.32)$ & $1.09(0.26)$ & $1.11(0.27)$ & $1.28(0.33)$ & $1.16(0.36)$ & $1.18(0.37)$ & $<0.001$ & $<0.001$ & $<0.001$ \\
\hline Diabetes (\%) & 1.6 & 3.3 & 5.3 & 10.1 & 14.0 & 12.8 & $<0.001$ & 0.40 & 0.40 \\
\hline Fibrinogen $(\mathrm{mg} / \mathrm{dl})$ & $360(99)$ & $410(121)$ & 379 (111) & $317(95)$ & $336(92)$ & $341(86)$ & $<0.001$ & $<0.001$ & $<0.001$ \\
\hline Factor VII $(\%)$ & $134(37)$ & $136(33)$ & $134(30)$ & $130(44)$ & $133(40)$ & $135(39)$ & $<0.001$ & 0.44 & 0.36 \\
\hline
\end{tabular}

Mean (S.D.). The PRIME study. 
Table 2

Relative risks ( $95 \%$ confidence intervals) of vascular events for one standard deviation increase in fibrinogen by country

\begin{tabular}{lllllll}
\hline & \multicolumn{2}{l}{ France } & & & \multicolumn{2}{l}{ Northern Ireland } \\
\cline { 2 - 3 } \cline { 5 - 6 } & Model 1 & Model 2 & & Model 1 & Model 2 \\
\hline Angina & $1.48(1.10-2.25) P=0.004$ & $1.36(1.03-2.08) P=0.03$ & & $1.27(0.93-2.19) P=0.18$ & $1.10(0.86-1.80) P=0.55$ \\
Hard CHD & $1.31(1.02-1.91) P=0.03$ & $1.18(0.94-1.67) P=0.18$ & & $2.26(1.36-4.45) P=0.0001$ & $1.90(1.19-3.73) P=0.002$ \\
Total CHD & $1.36(1.11-1.78) P=0.0009$ & $1.26(1.03-1.60) P=0.01$ & & $1.59(1.17-2.43) P=0.0008$ & $1.42(1.06-2.16) P=0.01$ \\
\hline
\end{tabular}

The PRIME Study. Model 1: adjusted for age. Model 2: adjusted for age, bmi, systolic blood pressure, TC, Hdl, diabetes, smoking status.

twofold difference in CHD incidence between the two countries. Factor VII activity adds little to the prediction of CHD risk.

The finding of a positive association between fibrinogen and CHD incidence is consistent with previous prospective cohort studies in United Kingdom [14-16], Sweden [17], Germany [18] and United States [19-21]. However, data evaluating the role of fibrinogen in determining the risk of angina pectoris are sparse. Elevated fibrinogen was a predictor of angina in the Edinburgh Artery Study but the association was no longer significant after adjustment for cardiovascular risk factors [16]. Our data show clearly that fibrinogen is an independent risk factor for angina, particularly in France.

Fibrinogen levels were substantially higher in Northern Ireland than France. This finding is consistent with our previous reports $[11,22]$. Another study investigated the differences in fibrinogen level between populations at contrasting risk for CHD. Japanese in the Akita Study have significantly lower fibrinogen levels than either European or African Americans and this difference is consistent with the higher rate of CHD mortality in the United States than Japan [23]. Minor changes in fibrinogen levels between the three French centers were observed at baseline [11]. These differences could not explain the geographical variations in CHD within France [10].

The mechanisms underlying the higher levels of fibrinogen in Northern Ireland compared with France remain speculative. Smoking is a major determinant of fibrinogen level. However, differences in fibrinogen levels between the two countries remained highly significant after adjustment for current or past smoking as well as for the dosage of tobacco consumption [11]. There were no substantial changes in the results after adjustment for other cardiovascular risk factors including educational level [11]. The differences could also be explained by a higher inflammatory response to infectious agents in men from Northern Ireland. However, no data are available in the PRIME Study to test this hypothesis.

Our data show that fibrinogen level has a stronger impact on the difference in CHD incidence between Northern Ireland and France than classical risk factors. About one third of the excess risk of CHD in Belfast compared with France may be explained in term of fibrinogen alone, while classical risk factors taken together account for only a quarter.

Whether elevated fibrinogen level may be causally related to atherothrombotic events remains unclear. High fibrinogen levels may be relevant to the pathogenesis of CHD through effects on blood viscosity, platelet aggregation, fibrin formation, and atheroma itself [4]. However, plasma fibrinogen is an acute phase protein and therefore, high levels may reflect the inflammation associated with atherosclerosis. The finding of a positive association between fibrinogen and the future development of angina suggests that elevated fibrinogen is not only relevant to thrombosis but also to atherosclerosis.

Genetic variations at the fibrinogen locus could explain in part the geographical differences in plasma

Table 3

Relative risks ( $95 \%$ confidence intervals) of coronary heart disease for Northern Ireland vs. France

\begin{tabular}{|c|c|c|c|c|c|c|}
\hline \multirow[t]{2}{*}{ Model } & \multicolumn{2}{|l|}{ Hard CHD } & \multicolumn{2}{|l|}{ Angina pectoris } & \multicolumn{2}{|l|}{ Total CHD } \\
\hline & $\mathrm{RR}(95 \% \mathrm{CI})$ & $\begin{array}{l}\text { Excess risk ex- } \\
\text { plained }(\%)\end{array}$ & $\mathrm{RR}(95 \% \mathrm{CI})$ & $\begin{array}{l}\text { Excess risk ex- } \\
\text { plained }(\%)\end{array}$ & $\mathrm{RR}(95 \% \mathrm{CI})$ & $\begin{array}{l}\text { Excess risk ex- } \\
\text { plained }(\%)\end{array}$ \\
\hline Unadjusted & $1.81(1.32-2.49)$ & - & $2.01(1.45-2.78)$ & - & $1.91(1.52-2.41)$ & - \\
\hline Adjusted for CRF & $1.59(1.15-2.21)$ & 27 & $1.77(1.26-2.48)$ & 24 & $1.68(1.32-2.13)$ & 25 \\
\hline Adjusted for Fibrinogen & $1.52(1.10-2.11)$ & 36 & $1.74(1.25-2.44)$ & 27 & $1.64(1.29-2.08)$ & 30 \\
\hline $\begin{array}{l}\text { Adjusted for CRF and } \\
\text { Fibrinogen }\end{array}$ & $1.42(1.01-1.98)$ & 48 & $1.62(1.14-2.30)$ & 39 & $1.51(1.18-1.94)$ & 44 \\
\hline
\end{tabular}

The PRIME Study. CRF: classical risk factors (age, bmi, systolic blood pressure, total cholesterol, HDL cholesterol, diabetes, smoking status); Hard CHD, future myocardial infarction or coronary death. 
fibrinogen level. Previous data in France and Northern Ireland showed no significant difference in fibrinogen genotypes between the two countries [22]. However, further genetic investigations in relation to geographical trends in CHD are required.

Several prospectives studies have investigated the association between factor VII and CHD incidence. The first Northwick Park Heart Study found a strong positive association between factor VII coagulant activity and the subsequent risk of MI [14]. Then, five studies $[16,18,19,21,24]$ failed to provide evidence that elevated factor VII was a predictor of CHD after adjustment for vascular risk factors. One hypothesis to explain the discrepancies between studies was the ability of factor VII assays to detect activated factor VII. The Northwick Park factor VII assay [13], which utilized a FVIIdeficient plasma depleted of protein $\mathrm{C}$, exhibited an increased responsiveness to activated factor VII in other factor VII assays, such as the Münster [18] or ARIC [19] assays, which used substrate plasma depleted of factor VII only [25]. A factor VII assay similar to those of the Northwick Park Heart Study was used in the PRIME Study and, therefore, an underestimation of activated factor VII can be excluded. However, activated factor VII has been related to both vascular risk factors [26] and CHD incidence [24] and further data evaluating the role of factor VIIa in CHD are needed.

The impact of factor VII genotype on factor VII activity and antigen is large, but conflicting results have been reported with respect to the risk of MI [27-29]. Interestingly, genotypes associated with low factor VII levels were significantly rarer in the northern part of Europe than in the southern part [30]. However, another geographical comparison showed that the frequency of the factor VII 353R/Q allele was similar in Northern Ireland and in France [27]. Further data are needed to clarify the factor VII genetic contribution to the development of CHD.

Potential limitations of our study include the fact that we evaluated only men aged 50-59 recruited both from industry and community settings. Therefore, the external validity of this study is limited and care must be taken when generalizing these data.

In conclusion, our data show that fibrinogen, but not factor VII, can explain much of the difference in risk of CHD between France and Northern Ireland. This finding add to the epidemiological evidence that elevated fibrinogen is a major risk factor for CHD.

\section{The PRIME study group}

The PRIME Study is organized under an agreement between INSERM and the Merck, Sharpe and DohmeChibret Laboratory, with the following participating Laboratories:
- The Strasbourg MONICA Project, Department of Epidemiology and Public Health, Faculty of Medecine, Strasbourg, France (D. Arveiler, B. Haas).

- The Toulouse MONICA Project, INSERM U558, Department of Epidemiology, Paul Sabatier-Toulouse Purpan University, Toulouse, France (J. Ferrières, JB. Ruidavets).

- The Lille MONICA Project, INSERM U508, Pasteur Institute, Lille, France (P. Amouyel, M. Montaye).

- The Department of Epidemiology and Public Health, Queen's University Belfast, Belfast, Northern Ireland (A. Evans, J. Yarnell).

- The Department of Atherosclerosis, SERLIA-INSERM U325, Lille, France (G. Luc, JM. Bard).

- The Laboratory of Haematology, La Timone Hospital, Marseilles, France (I. Juhan-Vague).

- The Laboratory of Endocrinology, INSERM U326, Toulouse, France (B. Perret).

- The Vitamin Research Unit, The University of Bern, Bern, Switzerland (F. Gey).

- The Trace Element Laboratory, Department of Medicine, The Queen's University, Belfast, Northern Ireland (D. McMaster).

- The DNA Bank, INSERM U525/SC7, Paris, France (F. Cambien).

- The Coordinating Center, INSERM U258, ParisVillejuif, France (P. Ducimetière, PY. Scarabin, A. Bingham).

\section{Acknowledgements}

We thank the following organizations which allowed the recruitment of the PRIME subjects: the Health screening centers organized by the Social Security of Lille (Institut Pasteur), Strasbourg, Toulouse and Tourcoing; Occupational Medicine Services of Haute-Garonne, of the Urban Community of Strasbourg; the Association Inter-entreprises des Services Médicaux du Travail de Lille et environs; the Comité pour le Développement de la Médecine du Travail; the Mutuelle Générale des PTT du Bas-Rhin; the Laboratoire d'Analyses de l'Institut de Chimie Biologique de la Faculté de Médecine de Strasbourg; the Department of Health (NI) and the Northern Ireland Chest Heart and Stroke Association.

\section{References}

[1] Tunstall-Pedoe H, Kuulasmaa K, Amouyel P, Arveiler D, Rajakangas AM, Pajak A. Myocardial infarction and coronary death in the world health organization MONICA project. Registration procedures, event rates, and case-fatality rates in 38 populations from 21 countries in four continents. Circulation 1994;90:583-612. 
[2] The WHO MONICA project. Geographical variations in the major risk factors of coronary heart disease in men and women aged 35-64 years, Wild Health Stat Quart 1988;41:115-36.

[3] Yarnell JWG. The PRIME study: classical risk factors do not explain the severalfold differences in risk of coronary heart disease between France and Northern Ireland. Q J Med 1998;91:667-76.

[4] Folsom A. Haemostatic risk factors for atherothrombotic disease: an epidemiologic view. Thromb Haemost 2001;86:366-73.

[5] Meade TW, Mellows S, Brozovic M, et al. Haemostatic function and ischaemic heart disease: principal results of the Northwick park heart study. Lancet 1986;ii:533-7.

[6] Scarabin PY. Haemostatic variables and arterial thrombotic disease: epidemiological evidence. In: Seghatchian MJ, Samama MM, Hecker SP, editors. Hypercoagulable states: fundamental aspects, acquired disorders, and congenital thrombophilia. CRC Press, 1996:209-16.

[7] Danesh J, Collins R, Appleby P, Peto R. Association of fibrinogen, C-reactive protein, albumin, or leukocyte count with coronary heart disease: meta-analyses of prospectives studies. J Am Med Assoc 1998;279:1477-82.

[8] Maresca G, Di Blasio A, Marchioli R, Di Minno G. Measuring plasma fibrinogen to predict stroke and myocardial infarction: an update. Arterioscler Thromb Vasc Biol 1999;19:1368-77.

[9] Rose GA, Blackburn H, Gillum RR, Privea RJ. Cardiovascular survey methods, 2nd ed.. Geneva: World Health Organization, 1982

[10] Ducimetière P, Ruidavets JB, Montaye M, Haas B, Yarnell J. Five-year incidence of angina pectoris and other forms of coronary heart disease in healthy men aged 50-59 in France and Northern Ireland: the PRIME study. Int $\mathbf{J}$ Epidemiol 2001;30:1057-62.

[11] Scarabin PY, Aillaud MF, Amouyel P, et al. Associations of fibrinogen, factor VII and PAI-1 with baseline findings among 10500 male participants in a prospective study of myocardial infarction. Thromb Haemost 1998;80:749-56.

[12] Clauss A. Gerinnungsphysiologische Schnellmethode zur Bestimmung des Fibrinogens. Acta Haematol 1957;17:237-46.

[13] Brozovic M, Stirling Y, Harricks C, North WRS, Meade TW. Factor VII in an industrial population. $\mathrm{Br} \mathrm{J}$ Haematol 1974;28:381-91

[14] Meade TW, Mellows S, Brozovic M, et al. Haemostatic function and ischaemic heart disease: principal results of the Northwick park heart study. Lancet 1986;ii:533-7.

[15] Yarnell JWG, Baker IA, Sweetnam PM, Bainton D, O'Brien JR, Whitehead PJ, Elwood PC. Fibrinogen, viscosity, and white blood cell count are major risk factors for ischemic heart disease. The Caerphilly and Speedwell collaborative heart disease studies. Circulation 1991;83:836-44.

[16] Smith FB, Lee AJ, Fowkes FRG, Price JF, Rumley A, Lowe GDO. Hemostatic factors as predictors of ischemic heart disease and stroke in the Edinburgh artery study. Arterioscler Thromb Vasc Biol 1997;17:3321-5.
[17] Wilhelmsen L, Svardsudd K, Korsan-Bengsten K, Larsson B, Welin L, Tibblin G. Fibrinogen as a risk factor for stroke and myocardial infarction. New Engl J Med 1984;311:501-5.

[18] Junker R, Heinrich J, Schulte H, van de Loo J, Assman G. Coagulation factor VII and the risk of coronary heart disease in healthy men. Arterioscl Thromb Vasc Biol 1997;17:1539-44.

[19] Folsom AR, Wu KK, Rosamond WD, Sharrett AR, Chambless LE. Prospective study of hemostatic factors and incidence of coronary heart disease. The atherosclerosis risk in communities (ARIC) study. Circulation 1997;96:1102-8.

[20] Kannel WB, Wolf PA, Castelli WP, D’Agostino RB. Fibrinogen and risk of cardiovascular disease: the Framingham Study. J Am Med Assoc 1987;258:1183-6.

[21] Tracy RP, Arnold AM, Ettinger W, Fried L, Meilahn E, Savage P. The relationship of fibrinogen and factors VII and VIII to incident cardiovascular disease and death in the elderly. Results from the cardiovascular health study. Arterioscl Thromb Vasc Biol 1999; 19:1776-83.

[22] Scarabin PY, Bara L, Ricard S, et al. Genetic variation at the beta-fibrinogen locus in relation to plasma fibrinogen concentrations and risk of myocardial infarction. Arterioscl Thromb 1993;13:886-91.

[23] Iso H, Folsom AR, Sato S, et al. Plasma fibrinogen and its correlates in Japonese and US population samples. Arterioscler Thromb 1993;13:783-90.

[24] Cooper JA, Miller GJ, Bauer KA, et al. Comparison of novel hemostatic factors and conventional risk factors for prediction of coronary heart disease. Circulation 2000;102:2816-22.

[25] Miller GJ, Stirling Y, Esnouf MP, et al. Factor VII-deficient substrate plasmas depleted of protein $\mathrm{C}$ raise the sensitivity of the factor VII bio-assay to activated factor VII: an international study. Thromb Haemost 1994;71:38-48.

[26] Scarabin PY, Vissac AM, Kirzin JM, Bourgeat P, Amiral J, Agher R, Guize L. Population correlates of coagulation factor VII: importance of age, gender, and menopausal status as determinants of activated factor VII. Arterioscl Thromb Vasc Biol 1996;16:1170-6.

[27] Lane S, Green FR, Scarabin PY, et al. Factor VII Arg/Gln353 polymorphism determines factor VII coagulant activity in patients with myocardial infarction (MI) and controls in Belfast and in France but is not a strong indicator of MI risk in the ECTIM Study. Atherosclerosis 1996;119:119-27.

[28] Iacovello L, Di Castelnuovo A, De Knijff P, et al. Polymorphisms in the coagulation factor VII gene and the risk of myocardial infarction. New Engl J Med 1998;338:79-85.

[29] Girelli D, Russo C, Ferraresi P, et al. Polymorphisms in the factor VII gene and the risk of myocardial infarction in patients with coronary heart disease. New Engl J Med 2000;343:774-80.

[30] Bernardi F, Arcieri P, Bertina RM, et al. Contribution of factor VII genotype to activated FVII levels: differences in genotype frequencies between northern and southern European populations. Arterioscler Thromb Vasc Biol 1997;17:2548-53. 